\title{
VARIABILIDADE DO REGIME PLUVIAL EM ABELARDO LUZ (SC) NO PERÍODO DE 1958 A 2008: INTERAÇÕES ENTRE MECANISMOS DE TELECONEXÃO DECADAL E INTERANUAL
}

\author{
BUFFON, Elaiz Aparecida Mensch - elaiz2@hotmail.com \\ Mestranda - Universidade Federal do Paraná - UFPR \\ BINDA, Andrey Luis - abinda@uffs.edu.br \\ Mestre em Geografia - Professor Assistente do curso de Geografia da Universidade Federal da Fronteira \\ Sul - UFFS - Chapecó
}

\begin{abstract}
RESUMO: Com presente trabalho busca-se analisar a variabilidade pluvial no município de Abelardo Luz (SC) no período de 1958 a 2008, visando, identificar relações da variabilidade pluvial com mecanismos de teleconexões, sobretudo, com a Oscilação Decadal do Pacífico (ODP) e com o El Niño Oscilação Sul (ENOS). Baseado em análise quantitativa (tratamento estatístico dos dados) e qualitativa (identificação dos fenômenos atuantes) foi possível correlacionar o regime pluviométrico com três fases da ODP, identificando importantes relações com o ENOS: a primeira, de 1958 a 1978 (fria), com predomínio de eventos de La Niña, reduzidos totais anuais/mensais e variados totais pluviais máximos diários por mês; a segunda, de 1979 a 1998 (quente), com maior frequência de El Niño, elevados totais anuais/mensais e totais pluviais máximos diários por mês com grande participação de eventos acima de 70 mm; e terceira, a partir de 1999 (nova fase fria), com relações semelhantes à primeira fase.
\end{abstract}

Palavras-chave: Precipitação, teleconexões, variabilidade pluvial, Abelardo-Luz (SC). PLUVIAL VARIABILITY OF MUNICIPALITY OF ABELARDO LUZ (SC) IN PERIOD OF 1958 TO 2008: INTERACTIONS BETWEEN MECHANISMS OF DECADAL AND INTERANUAL TELECONNEXIONS

ABSTRACT: This study aims to analyze the variability of rainfall in the city Abelardo Luz (SC) in the period 1958-2008 and its relation with teleconnection patterns mechanisms, especially with the Pacific Decadal Oscillation (PDO) and the El Niño Southern Oscillation (ENSO). Based on quantitative analysis (statistical data) and qualitative (identification of active phenomena) it was possible to correlate the rainfall regime three phase PDO with important relationships with ENSO: the first from 1958 to 1978 (cold) with a predominance of events La Niña, reduced total annual/monthly and varied daily maximum per month, the second from 1979 to 1998 (hot) with higher frequency of El Niño, elevated total annual/monthly and daily maximum per month with great participation of events above $70 \mathrm{~mm}$, and the third from 1999 (new cold phase) with relations similar to the first phase.

Key-words: Precipitation, teleconnection patterns, rain variability, Abelardo-Luz (SC).

\section{INTRODUÇÃO}

Clima é um termo atribuído ao fenômeno sistêmico, dinâmico e natural produzido pelas interações entre o sistema Sol-Atmosfera-Terra e, responsável por influências significativas nas principais bases da vida na Terra (MOLION, 2005; AYOADE, 2010). Para Max Sorre apud Mendonça \& Danni Oliveira (2007, p.15), o clima corresponderia a "série dos estados atmosféricos acima de um lugar em sua sucessão habitual". Monteiro (1971), valendo-se do conceito apresentado por Sorre, desenvolveu o paradigma da análise rítmica, como forma de melhor compreender os aspectos climáticos de um dado local. Desse modo, tal como se pode imaginar, a atmosfera não é estática e, além do mais, alguns mecanismos de teleconexão podem afetar o padrão climático, exercendo alterações não somente nos elementos climáticos, mas também nas variáveis meteorológicas. Essas influências são diferentes de uma localidade para outra, pois o clima varia no espaço e no tempo, assim como interage com elementos, ele é influenciado pelos fatores geográficos (MENDONÇA e DANNI-OLIVEIRA, 2007), bem como por fenômenos de larga escala (GRIMM, 2009a; CAVALCANTI \& AMBRIZZI, 2009; MOLION, 2005).

Dentre os vários fenômenos que afetam e controlam os aspectos da variabilidade climática na região sul, cita-se aqueles cuja interferência ocorre por meio de interações entre o oceano e a atmosfera. Esses fenômenos identificados por meio de alterações da Temperatura da 
Superfície do Mar (TSM) podem se manifestar tanto de modo interanual, tal como o El Niño Oscilação Sul (ENOS), (ENSO - El Niño South Oscilation), como decadal, relacionado a Oscilação Decadal do Pacífico (ODP) (PDO - Pacific Decadal Oscillation) (MENDONÇA \& DANNIOLIVEIRA, 2007; CAVALCANTI \& AMBRIZZI, 2009; MOLION, 2005).

O ENOS corresponde ao principal mecanismo de teleconexão interanual que afeta o regime de precipitação da América do Sul e, portanto, vem sendo estudado por diversos autores tanto em aspectos regionais (ANDRADE, 2003; NERY, 2006), como locais (MOTA, 2000). A classificação da intensidade do ENOS é feita considerando as alterações na TSM, na pressão e, nos ventos alísios da região do Pacífico Equatorial (GRIMM, 2009a). Esses comportamentos influenciam a circulação da célula de Walker, que promove teleconexões com diferentes respostas em diversas localidades do globo (MENDONÇA \& DANNI-OLIVEIRA, 2007; CAVALCANTI \& AMBRIZZI, 2009). No Brasil, segundo Grimm (2009a), durante a ocorrência de EN (LN), observa-se aumento (diminuição) de chuvas no Sul do Brasil, sendo que nas regiões Norte-Nordeste a resposta é oposta. Esses fenômenos apresentam diferentes retrospectos socioambientais, tais como inundações/enchentes e estiagens.

No que refere-se aos mecanismos de teleconexão, em escala temporal mais ampla, ou seja, decadal, apresenta-se a ODP. Essa teleconexão está associada à TSM do Oceano Pacífico, composta inclusive por anomalias negativas de temperaturas no Pacífico Tropical e positivas no Pacífico Extratropical (fase fria - ODP-) ou anomalias positivas de temperaturas no Pacífico Tropical e negativas no Pacífico Extratropical (fase quente - ODP+) (MOLION, 2005). Nesse sentido, Silva et al. (2010), Rebello, (2009), Oliveira et al., (2006) e Molion (2005) têm demonstrado que durante as fases da ODP+ (ODP-) observa-se maior quantificação de casos de teleconexão interanual do tipo El Niño (La Niña).

Tendo em vista os retrospectos socioambientais do fenômeno ENOS, nas distintas fases, evidencia-se que durante a ocorrência da fase da ODP positiva, o Brasil, principalmente as regiões Sul e Nordeste, são afetados por desastres naturais, ocasionados pelo excesso de chuva, apresentando-se na forma de enchentes e/ou inundações, deslizamentos, vendavais e outros (MARCELINO, 2008; ANDRADE, 2003). Do lado oposto, nos períodos de ocorrência da fase negativa da ODP presenciaram-se, igualmente, desastres naturais em virtude da escassez de chuvas (secas e estiagens), afetando a sociedade por meio da falta de água, baixa na produtividade agrícola e, possíveis doenças ligadas ao aparelho respiratório (MOTA, 2000; ALEIXO, 2012).

Esses desastres são decorrentes, portanto, dos contrastes espaços-temporais nos regimes de precipitação (GRIMM, 2009b), fato que permite a utilização, neste trabalho, do conceito de variabilidade climática, como sendo a "...maneira pela qual os parâmetros variam no interior de um determinado período de registro, expressos através de desvio-padrão ou coeficiente de variação" (OMM, 1966 apud CONTI, 2000, p.20). Estudos das relações entre a precipitação e os mecanismos de teleconexões são importantes tanto em escala global, regional, bem como local, isso por que, conforme Silva \& Campos (2011), os mecanismos de teleconexões, tipo ENOS e ODP, exercem influência de modo diversificado. Sob essa perspectiva, o presente trabalho visa analisar a variabilidade anual e sazonal da precipitação no município de Abelardo Luz (SC) no período de 1958 a 2008, visando, desse modo, verificar as possíveis relações com os mecanismos de teleconexões em escala interanual e decadal.

\section{MATERIAIS E METÓDOS}

\section{Localização e Características Gerais da Área de Estudo}

O município de Abelardo Luz está localizado na Mesorregião Oeste Catarinense e faz limite com os municípios de São Domingos-SC e Ipuaçu-SC a oeste, Ouro Verde-SC e Faxinal dos Guedes-SC ao sul, Vargeão-SC e Passos Maia-SC a leste e Palmas-PR e Clevelândia-PR ao 
norte (Figura 2). Possui área territorial de $955,38 \mathrm{~km}^{2}$ e aproximadamente 17.100 habitantes $\left(\right.$ IBGE, 2010 ${ }^{1}$ ).

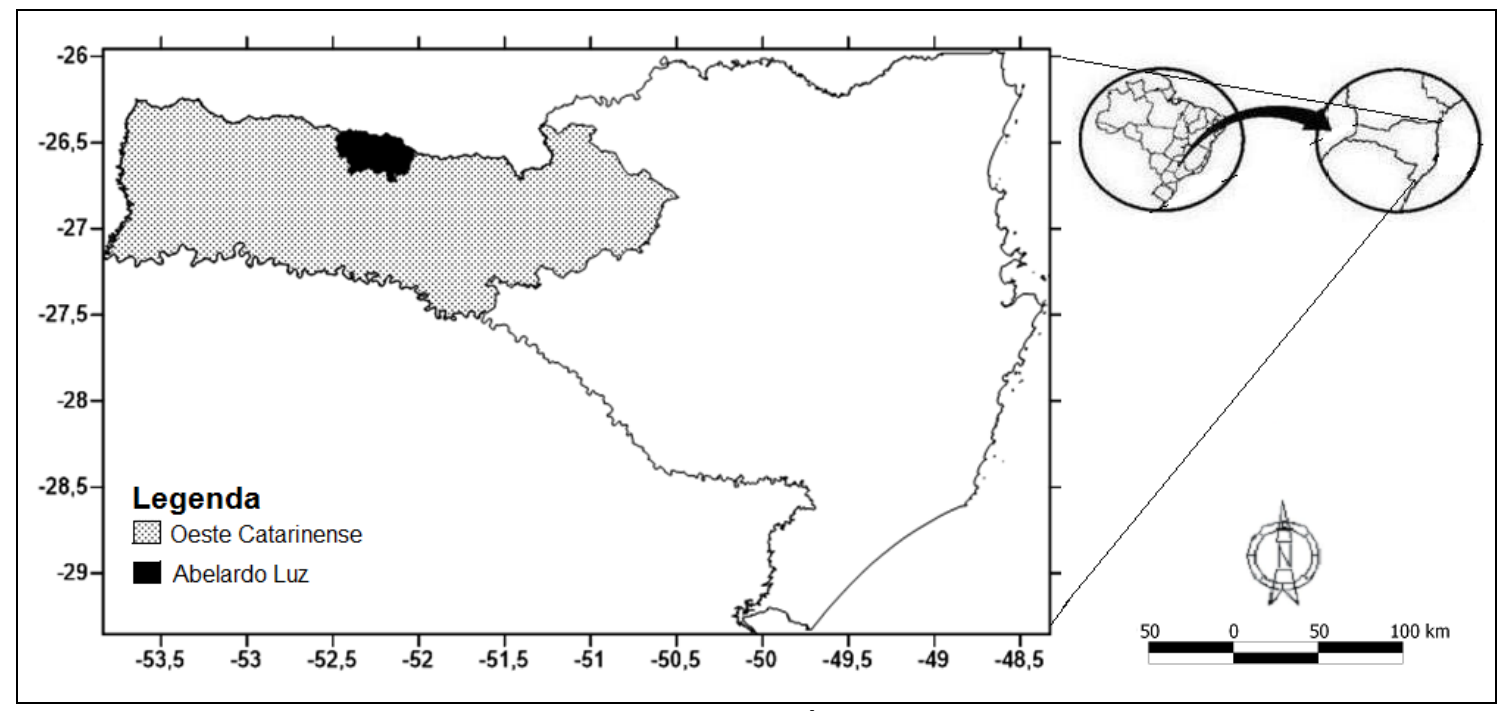

Figura 1: Localização do município de Abelardo Luz/SC.

Organização: Buffon (2013).

Abelardo Luz encontra-se sobre o planalto oeste do Rio Uruguai (PELUSO JÚNIOR, 1986) pertencente a Serra Geral, com altitudes em torno dos 760 metros que evidenciam relevos fortes e ondulados, suportado por rochas efusivas da Formação Serra Geral (SCHEIBE, 1986; NARDY, 1995) e drenado pelos rios Chapecó e Chapecozinho. O clima do município de Abelardo Luz é caracterizado como Subtropical Úmido ou Mesotérmico do Tipo Temperado, com temperaturas inferiores e geadas no inverno, ocasionadas pela passagem de frentes frias pela região, a precipitação pluvial é distribuída regularmente ao longo do ano, embora existam desvios positivos (El Niño) e negativos (La Niña) (NIMER, 1989; MENDONÇA \& DANNIOLIVEIRA, 2007). A Floresta Ombrófila Mista representa a vegetação natural da área, a qual se encontra intensamente alterada pelas atividades antrópicas. Por fim, a base da econômica é a agropecuária, embora o comércio e o turismo também possuam destaque (PREFEITURA MUNICIPAL DE ABERLARDO LUZ, $2011^{2}$ ).

\section{Descrição da Pesquisa}

Os dados utilizados para a caracterização do regime pluvial do município de Abelardo Luz-SC foram obtidos por meio do acesso ao banco de dados Hidroweb (http://hidroweb.ana.gov.br), da Agência Nacional das Águas (ANA). A estação pluviométrica utilizada (código 02652000 de responsabilidade da ANA e monitorada pelo Serviço Geológico do Brasil-CPRM) encontra-se localizada a $26^{\circ} 33^{\prime} 22^{\prime \prime} \mathrm{S}$ e $52^{\circ} 19^{\prime} 51^{\prime \prime} \mathrm{W}$, a $760 \mathrm{~m}$ de altitude. A série histórica de precipitação diária utilizada corresponde ao período de 1958 a 2008, compreendendo 51 anos de dados. Mediante o uso da planilha LibreOffice Calc, os dados diários foram organizados mensalmente e anualmente. A fim de calcular o coeficiente de variação anual da pluviosidade, utilizou-se da seguinte equação (SANT“ANNA NETO, 1990 apud NASCIMENTO JÚNIOR, 2010 (adaptado)):

$$
C V P=[(X 1-M) / M] \ldots \ldots \ldots \text { (Equação } 1)
$$

\footnotetext{
${ }^{1}$ Disponível em: <http://www.ibge.gov.br/cidadesat/link.php?uf=sc>. Acesso em 15/12/2010.

${ }^{2}$ Disponível em: <http://www.abelardoluz.sc.gov.br/conteudo/?item=17736\&fa=334\#> Acesso em 15/12/2010.
} 
onde, CVP: coeficiente de variação anual da pluviosidade; X1: total pluvial anual e M: média dos totais pluviais compreendendo a série histórica.

O cálculo do coeficiente de variação anual da pluviosidade é de suma importância para estudos que visam apresentar a variabilidade, uma vez que demonstram a relação positiva ou negativa em relação à média climatológica de precipitação para o município.

Para a definição dos anos padrão foi aplicada a metodologia proposta por Sant"Anna Neto (1990) e usada por Tavares et al. (2004) e Nascimento Júnior (2010), cujo foco central é verificar a variação dos totais pluviais anuais, mediante a identificação do desvio padrão em milímetros (equação 2) e das porcentagens anuais (equação 3):

$$
\begin{aligned}
& \mathrm{DP}(\mathrm{mm})=\mathrm{X} 1-\mathrm{M} \ldots \ldots \ldots . .(\text { Equação } 2) \\
& \mathrm{DP}(\%)=[\mathrm{DP}(\mathrm{mm}) / \mathrm{M})]^{*} 100 \ldots \ldots \ldots . .(\text { Equação } 3)
\end{aligned}
$$

Onde: DP (mm): desvio padrão em milímetros; DP (\%): desvio padrão em porcentagem; X1: total pluvial anual e; M: média dos totais pluviais compreendendo a série histórica.

Com base nas equações 2 e 3, classificaram-se os totais pluviais anuais em anos seco, tendente a seco, habitual, tendente a chuvoso e chuvoso, conforme utilizado por Nascimento Júnior (2010) (Tabela 1).

Tabela 1: Proposta de classificação dos anos-padrão.

\begin{tabular}{c|c|c|c}
\hline CLASSE & FÓRMULAS & $\begin{array}{c}\text { FORMATAÇÃo } \\
\text { CONDICIONAL }\end{array}$ & COR \\
\hline Seco & T-DP $(\mathrm{mm})$ & $\begin{array}{c}\text { Valores menores/iguais a } \\
\text { Seco }\end{array}$ & Amarelo \\
\hline $\begin{array}{c}\text { Tendente a } \\
\text { seco }\end{array}$ & $\mathrm{T}$-[DP(mm)/2] & Valores entre Seco e Habitual & Laranja \\
\hline $\begin{array}{c}\text { Habitual } \\
\text { chuvoso }\end{array}$ & $-\mathrm{T}+[\mathrm{DP}(\mathrm{mm}) / 2]$ & $\begin{array}{r}\text { Valores entre Habitual e } \\
\text { Chuvoso }\end{array}$ & Azul claro \\
\hline $\begin{array}{c}\text { Chuvoso } \\
\text { Chunco }\end{array}$ & $\mathrm{T}+\mathrm{DP}(\mathrm{mm})$ & $\begin{array}{r}\text { Valores maiores/iguais a } \\
\text { Chuvoso }\end{array}$ & Azul escuro \\
\hline
\end{tabular}

Fonte: NASCIMENTO JÚNIOR (2010). Org.: Buffon (2013).

Para a representação dos totais pluviais e eventos máximo diários por mês, baseou-se na média (Equação 4), no desvio padrão (Equação 5) e no respectivo total pluvial e evento 
extremo para cada mês. Assim, foi possível apresentar temporalmente os meses e os anos caracterizados por apresentar precipitação em torno da média, inferiores e superiores. A mesma ideia foi empregada nos eventos máximos diários por mês. A representação dessas informações foi apresentada por meio da confecção de figuras no software Surfer Demo Version 10. 7. 972, desenvolvido pelo Copyright@ Golden Softwares Inc. 2012.

$$
\bar{x}=\frac{\sum x_{i}}{n} \ldots . . . . . .(\text { Equação } 4)
$$

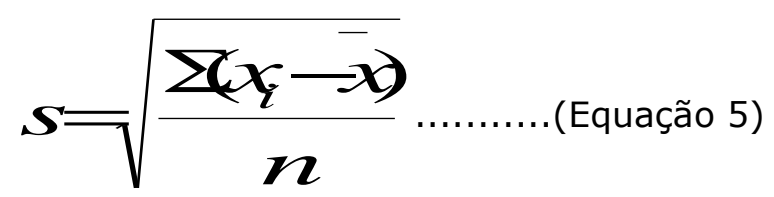

Ainda, para caracterizar a pluviosidade mensal e anual foi calculado a média mensal e o respectivo desvio padrão mensal, a fim de apresentar os meses padrão. Os cálculos para identificação desses meses foram realizados e representados seguindo a Tabela 1. A caracterização e intensidade das fases do ENOS foram fundamentadas na proposta de Galvani e Pereira (1997) e nas que estão disponíveis no site do Centro de Previsão de Tempo e Estudos Climáticos (CPTEC), do Instituto Nacional de Pesquisas Espaciais (INPE) (<http://enos.cptec.inpe.br/>). Essas caracterizações são baseadas no Índice de Oscilação Sul (IOS) e nas anomalias de TSM.

\section{RESULTADOS E DISCUSSÕES}

Para caracterização e intensidade das fases do ENOS elaborou-se o gráfico apresentado na Figura 2, sendo que os valores, na escala de 1, 2 e 3 para o El Niño e, -1, -2 e -3 para a La Niña, indicam, respectivamente, eventos de intensidade fraca, moderada e forte. Observa-se maior concentração de El Niño nas décadas de 80 e 90, enquanto que a de La Niña ocorreu predominantemente nas décadas de 60, 70 e após meados da década de 90 . 


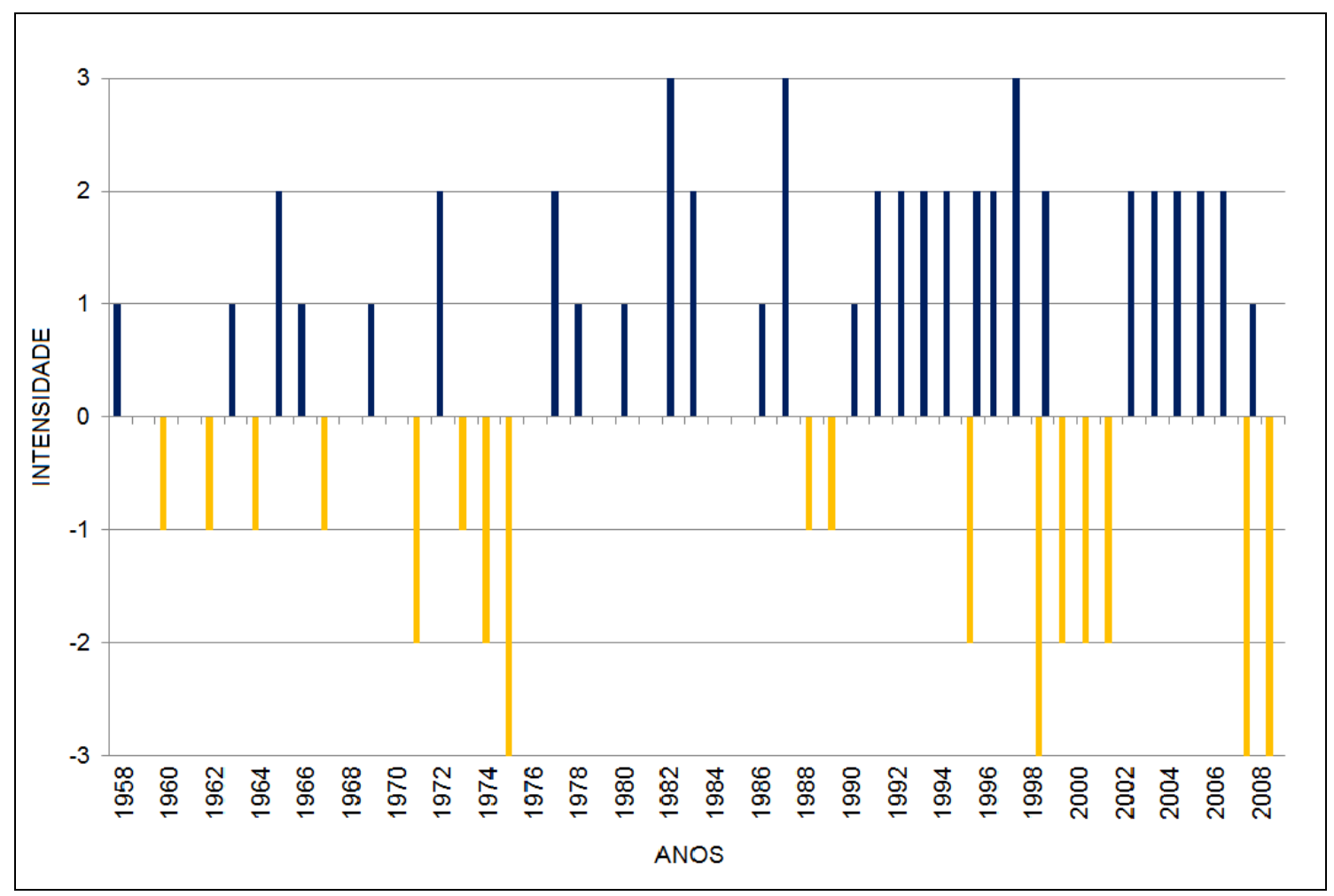

Figura 2: Ocorrência e intensidade do ENOS entre 1958 a 2008.

Fonte: GALVANI \& PEREIRA (1997); CPTEC (2012). Org.: Buffon (2012).

As variações na frequência de ocorrências do fenômeno ENOS são uma das causas nas mudanças de temperatura global (MOLION, 2008a), interferindo diretamente na precipitação. Como mencionado anteriormente, esse processo relaciona-se diretamente com ODP. Na Figura 3, é possível identificar os períodos de ocorrência de cada uma das fases da ODP no período entre 1900 e 2000. Ademais, para Molion (2005), a última ODP+ ocorreu no período de 1977 a 1998, enquanto que a última ODP-, sucedeu aproximadamente entre 1947 a 1976, além de indícios de uma possível ODP- a partir de 1999.

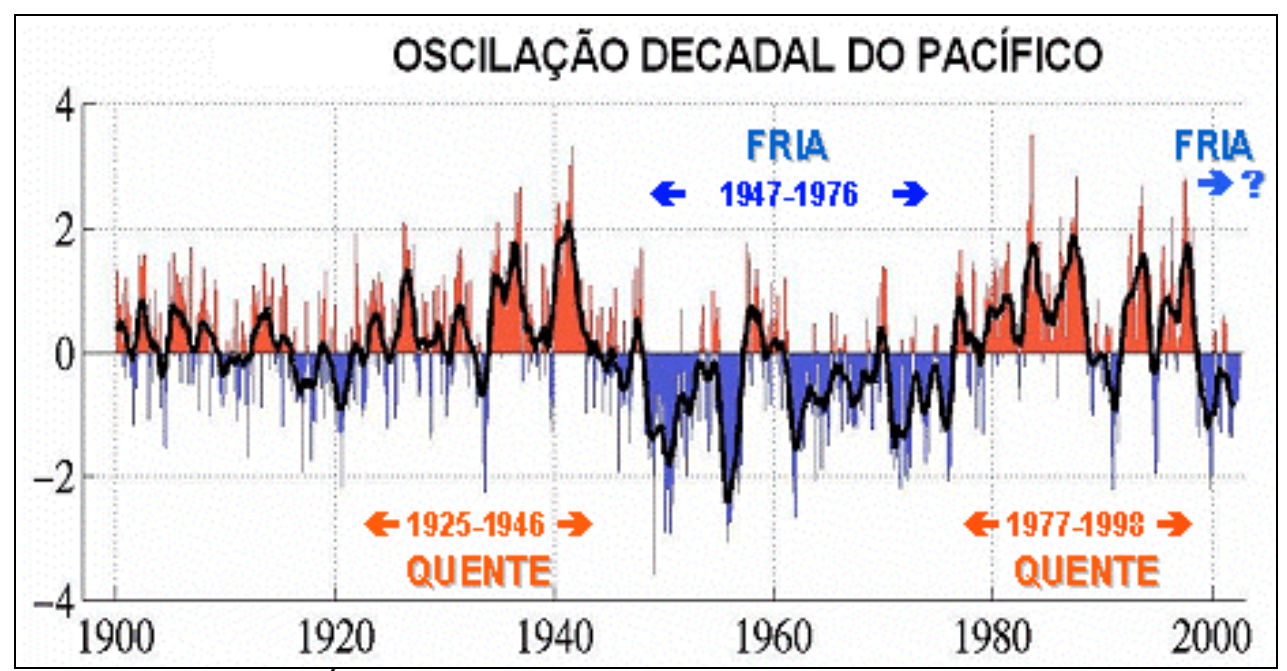

Figura 3: Série temporal do Índice da Oscilação Decadal do Pacífico (Mantua et al, 1997). Fonte: Molion (2005).

Considerando a Figura 3, no período de 1958 a 2008, presenciou-se a atuação do El Niño durante 34 anos, enquanto que a La Niña atuou em 21 anos. Destaca-se maior ocorrência de 
episódios de El Niño entre 1979 a 1998 (14 episódios), principalmente para os eventos de intensidade forte. Por outro lado, a La Niña obteve maior ocorrência e intensidade no período entre 1958 e 1978 (8 episódios), bem como a partir de 1999 (5 episódios), o que corrobora para a atuação de duas fases distintas da -ODP (Figura 2).

Digno de nota, é que houve grande alternância entre os anos habituais, tendente a seco, tendente a chuvoso, seco e chuvoso, o que remete à condição de ocorrência intercalada entre eles. No entanto, pode-se perceber que os anos tendente a chuvoso ou chuvoso apresentam maior ocorrência, justamente no período entre 1978 a 1998 (8 eventos), associando-se, assim, com a fase quente do ODP. De modo inverso, anos tendente a seco e seco ocorreram predominantemente em dois períodos distintos, entre 1958 a 1977 ( 9 eventos) e a partir de 1998 (6 eventos), também correlacionáveis com os eventos da fase fria do ODP.

Ao longo da série histórica estudada, alguns anos merecem destaque. Chama-se atenção para os eventos consecutivos de anos chuvosos entre 1979 a 1984, os quais foram responsáveis por grandes desastres naturais e perdas econômicas ocorridas na Região Sul (MARCELINO et al., 2005; ANDRADE, 2003; MOTA, 2000). Quanto aos eventos de anos tendentes a secos e secos, Buffon \& Binda (no prelo) relatam que a década de 60 foi responsável pela maior quantificação dos casos de estiagem em Abelardo Luz-SC, sendo esses também os casos mais significativos da série histórica de quatro décadas de estudo.

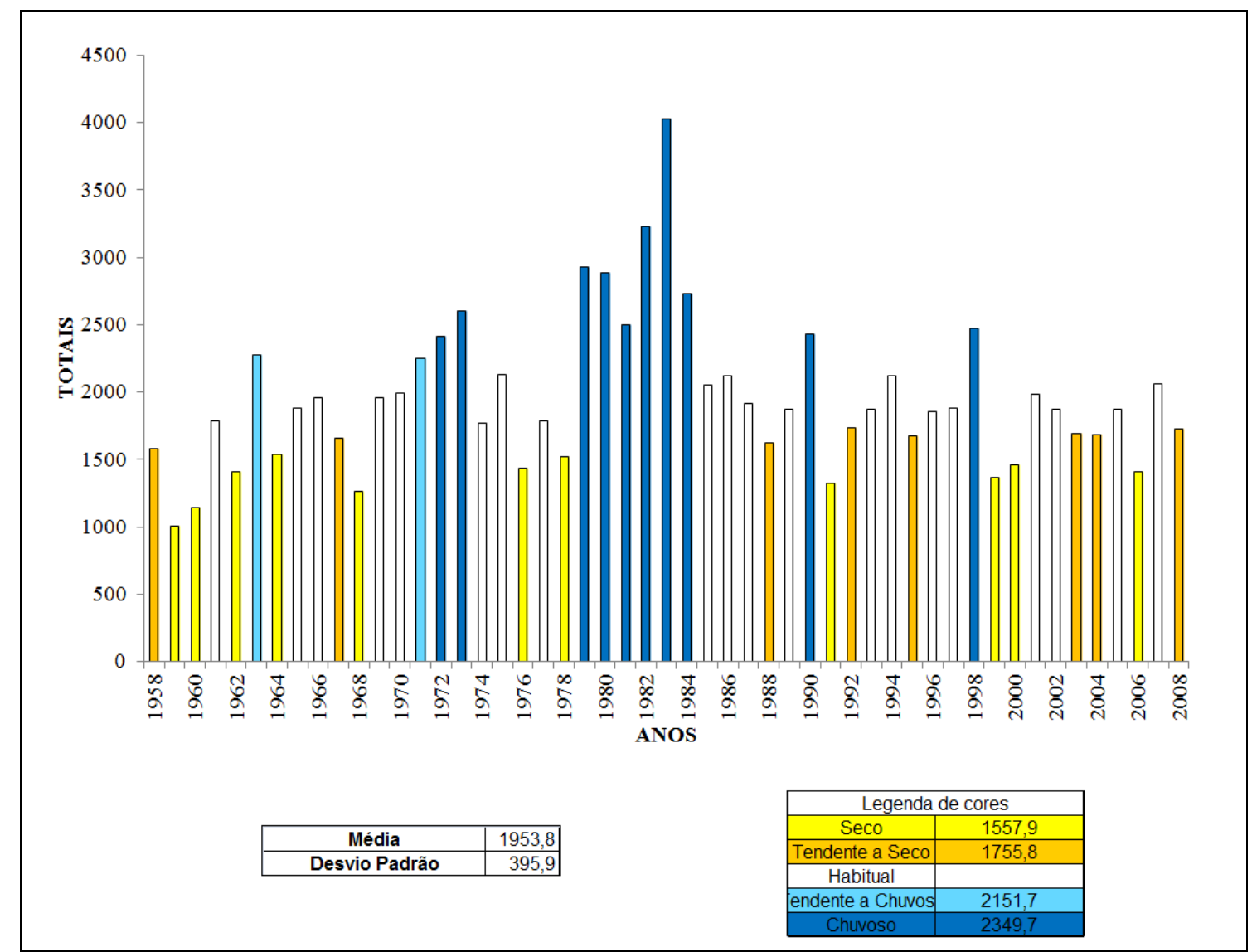

Figura 4: Variabilidade da pluviosidade anual da precipitação no município de Abelardo Luz-SC. Fonte: ANA (2010). Org. Buffon (2013).

Com a finalidade de clarificar as relações entre as ocorrências de episódios de El Niño e La Niña, associadas ao fenômeno da ODP, baseou-se no coeficiente de variação anual de pluviosidade. Durante o período de 1958 a 1978, interpretado neste trabalho como fase fria 
da ODP, registram-se 14 anos com coeficientes negativos e apenas seis anos com os coeficientes positivos (Figura 5). Entretanto, a partir de 1979 até 1998, os coeficientes negativos representam ocorrências, ao passo de que coeficientes positivos passam a 11 eventos (Figura 5). É importante chamar atenção aos elevados valores registrados para os anos com coeficientes positivos, sobretudo, entre 1979 e 1984, fato que denota uma fase quente da ODP. De 1999 até o final da série analisada, é possível identificar a ocorrência de 8 anos de coeficientes negativos e somente 3 anos com coeficientes positivos, o que demonstra, realmente, o alvorecer de uma nova fase fria da ODP (Figura 5).

Na mesma perspectiva, outros autores também apontam associações entre a variabilidade decadal da precipitação e a ODP. Molion (2008b) conclui que a ODP demonstrou correlações, em partes, com a variabilidade pluvial ocorrida em algumas das bacias, tais como: do rio Paranapanema e do rio Paraná. No mesmo enfoque, Nascimento Júnior (2011) verifica relações entre as fases da ODP e a variabilidade da precipitação em Foz do Iguaçu, Quedas do Iguaçu e São Miguel do Iguaçu, no estado do Paraná. Sperling et al. (2009) também demonstraram a influência da ODP na variabilidade da precipitação do estado de Rio Grande do Sul. Molion (2005) salienta, ainda, que a posição geográfica das estações meteorológicas podem afetar parcialmente 0 início e o término dos períodos da ODP apresentados, evidenciando, assim, como as respostas climáticas são complexas. Esse aspecto pode ser percebido no presente trabalho, isso por que, Molion (2005) ressalta o ano de 1976, como o final da ODP negativa (fase fria) e 1977 e o início da ODP positiva (fase quente) e, neste trabalho, obteve-se como final da fase fria o ano de 1978 e, início da fase quente o ano de 1979.

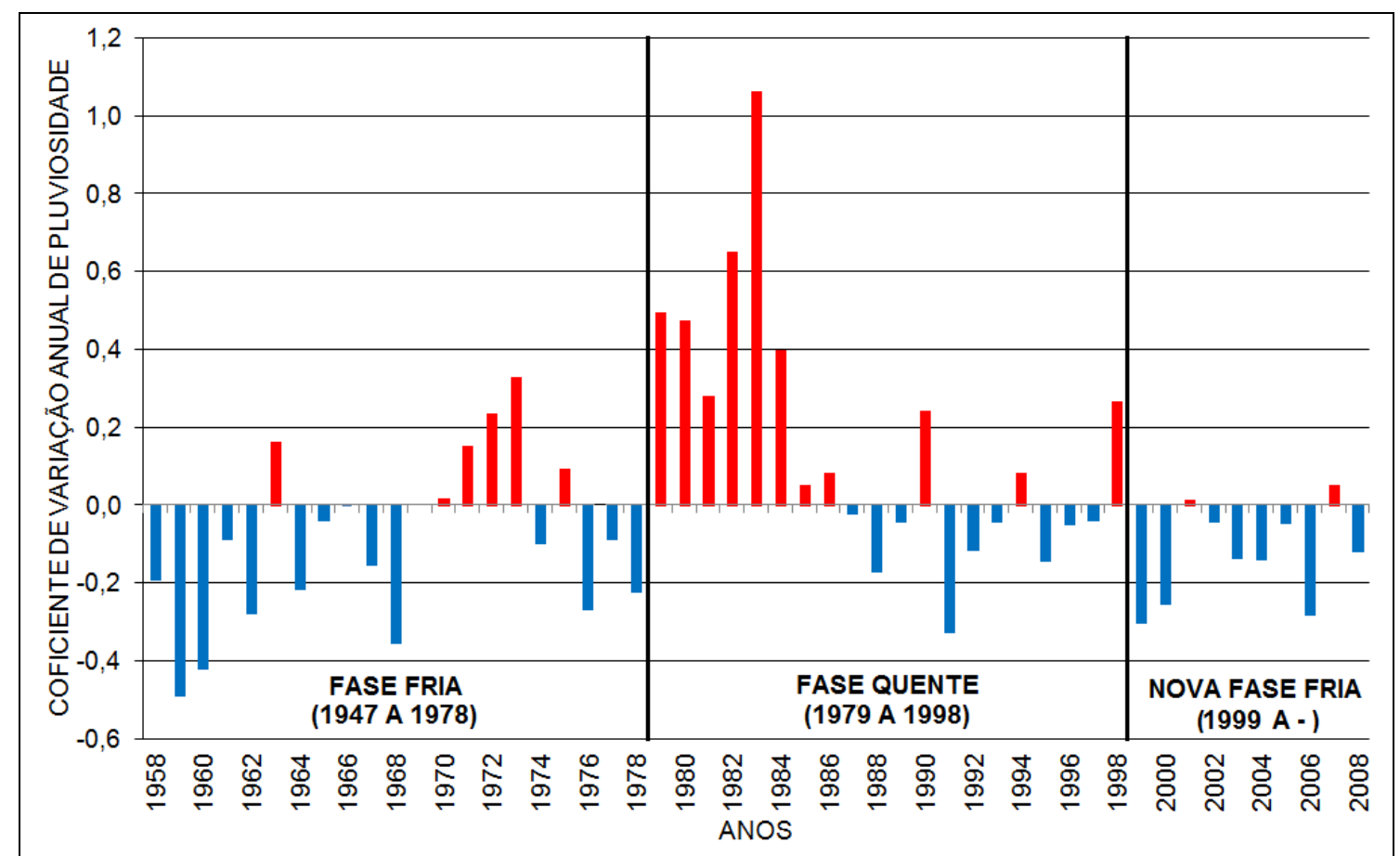

Figura 5: Variabilidade decadal dos dados pluviais do município de Abelardo Luz-SC de 1958 a 2008. Fonte: ANA (2010). Org.: Buffon (2013).

Frente a isso, é válido mencionar que existe determinada relação entre a variabilidade decadal da pluviosidade do município de Abelardo Luz-SC com a ODP, uma vez que os períodos apontados pelas fases fria e quente desse fenômeno de escala maior se correlacionam com os períodos de maior ocorrência de El Niño (La Niña), que estão associados ao fenômeno ENOS. 
Para verificar a possível influência do ENOS e da ODP elaborou-se a Tabela 2, que apresenta a média e o desvio padrão e, a Figura 6 , onde são representados os totais mensais, meses padrão e o máximo diário por mês. Os dados da Tabela 2 apontam, inicialmente, médias mensais mais elevadas, durante os meses do Verão e Primavera, enquanto, no Inverno e Outono as médias mensais sofrem redução. Além disso, observa-se que os valores máximos do desvio Padrão ocorreram nos meses de maio e junho e, que os valores mínimos aconteceram nos meses de março, junho e setembro, o que conduz a ocorrência de eventos excepcionais máximos e/ou mínimos nesses meses.

Tabela 2: Média mensal $(\mathrm{mm})$ e desvio padrão mensal $(\mathrm{mm})$ da precipitação no município de Abelardo Luz (SC) para o período de 1958 a 2008.

\begin{tabular}{ccc}
\hline Meses & Média Mensal $(\mathbf{m m})$ & Desvio Padrão $(\mathbf{m m})$ \\
\hline Janeiro & 180,2 & 91,6 \\
Fevereiro & 169,2 & 93,0 \\
Março & 146,8 & 75,6 \\
Abril & 151,6 & 86,8 \\
Maio & 154,3 & 118,9 \\
Junho & 146,0 & 74,3 \\
Julho & 143,6 & 112,1 \\
Agosto & 143,4 & 80,4 \\
Setembro & 179,0 & 74,5 \\
Outubro & 213,1 & 93,8 \\
Novembro & 158,4 & 88,8 \\
Dezembro & 168,0 & 94,5 \\
\hline
\end{tabular}

Org.: Buffon (2013). 


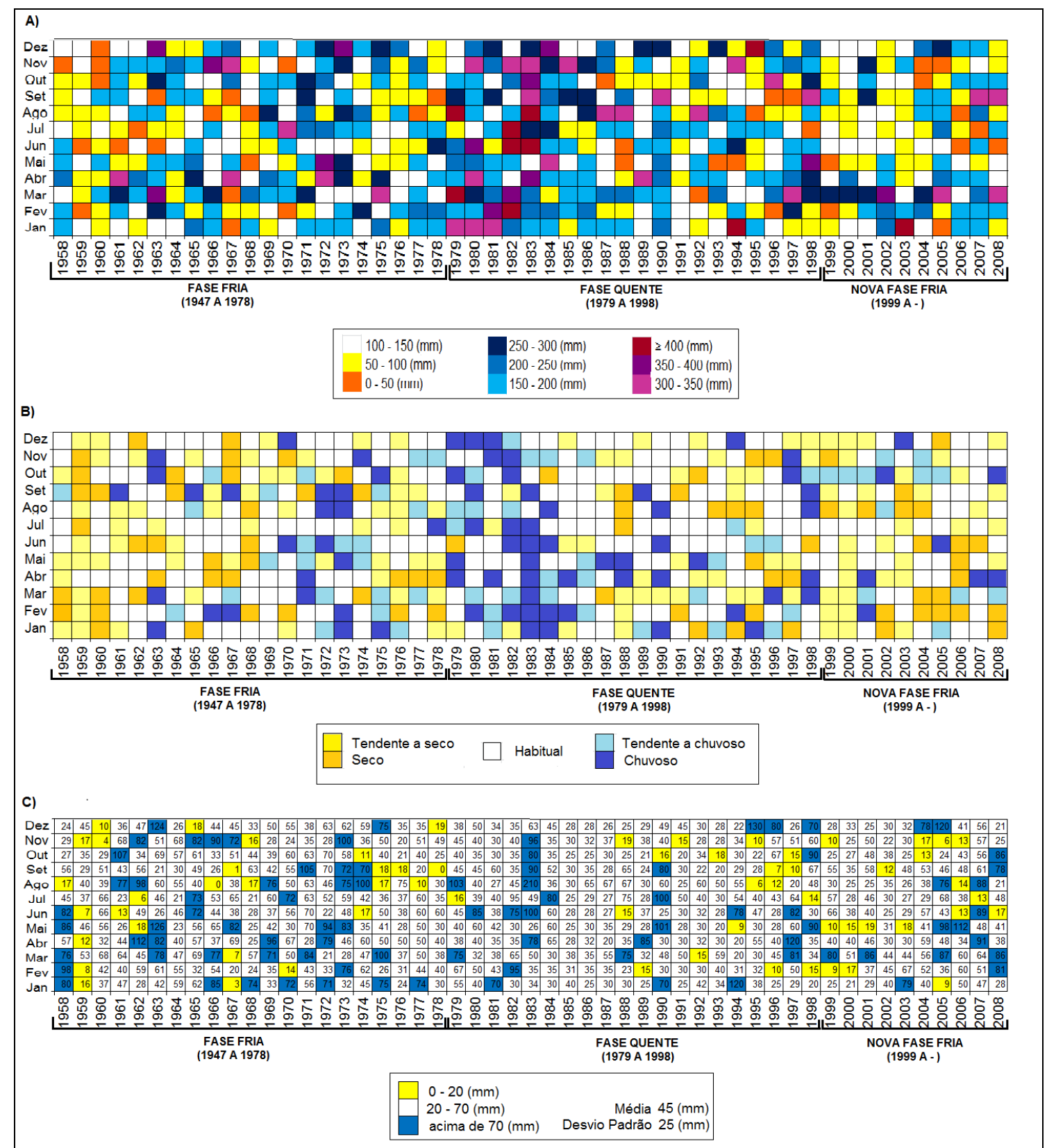

Figura 6: A) Totais pluviais mensais para o município de Abelardo Luz (SC) no período de 1958 a 2008 ; B) Variação da pluviosidade mensal e anual no município de Abelardo Luz (SC); C) Totais pluviais máximas diários por mês no período de 1958 a 2008.

Fonte: ANA (2010). Org.: Buffon (2013).

Mediante a figura $6 \mathrm{~A}$, depreende-se que a redução (aumento) dos totais anuais aos longos das fases frias (quentes) da ODP, deve ser correlacionável com a redução (aumento) nos totais mensais desses anos. Dessa forma, pode-se verificar que os anos de 1958 e 1959 apresentaram, por exemplo, a ocorrência de meses com precipitação reduzida, ao passo que em 1982 e 1983 predominaram meses com maior pluviosidade. Meses caracterizados como habituais, ou seja, em torno da média, demonstraram ocorrência dispersa em todos os anos, com a menor ocorrência mensal nos anos citados acima, que são reconhecidos pelos eventos de estiagem e inundações/enchentes verificadas no estado de Santa Catarina.

Os totais mensais de 0 a $150 \mathrm{~mm}$ e de 300 a $400 \mathrm{~mm}$ predominaram, respectivamente, em anos das fases frias e quente da ODP. Já os totais mensais, que variam de 150 a $300 \mathrm{~mm}$ foram identificados em ambas às fases da ODP. Para contribuir nessa análise dos totais 
pluviais, apresenta-se na Figura 6B a intensificação de meses tendente a chuvoso e chuvoso ao longo da fase quente da ODP, da mesma forma que os meses tendentes a seco e seco foram marcantes na fase fria da ODP. Frisa-se que durante a fase fria da ODP, que vigorou quatro anos $(1959,1960,1962$ e 1968), foi caracterizada apenas por meses seco, tendente a seco e habitual. Durante a fase quente da ODP, apenas dois anos (1980 e 1983) obtiveram somente meses chuvoso, tendente a chuvoso e habitual (Figura 6B).

Quanto aos eventos máximos diários por mês (Figura 6C), observa-se que houve tantos eventos superiores a $70 \mathrm{~mm}$, como inferiores a $20 \mathrm{~mm}$ nas fases frias e quentes. Nota-se que os eventos máximos diários por mês concentraram-se de $20 \mathrm{~mm}$ a $70 \mathrm{~mm}$ em ambas as fases, de modo, que 62 eventos inferiores a $20 \mathrm{~mm}$, sendo 27 eventos na fase fria da ODP, 18 eventos na fase quente e 17 eventos na nova fase fria da ODP. Além disso, salienta-se dois eventos mínimos de $0 \mathrm{~mm}$, tendo esses dois eventos ocorridos na fase fria da ODP. Quanto aos eventos superiores a $70 \mathrm{~mm}$, verificaram-se 88 eventos, com um evento de $210 \mathrm{~mm}$ e 17 eventos superiores a $100 \mathrm{~mm}$, de modo que, 7 eventos ocorreram na fase quente da ODP, 8 eventos aconteceram na fase fria da ODP e 2 eventos sucederam na nova fase fria da ODP. Embora, os eventos máximos por mês com elevados e/ou totais tenham se distribuído ao longo de todo o período, elencam-se associações entre os períodos notórios descritos acima e a ODP. Ademais, os eventos mais significativos de elevados (inferiores) totais diários máximos por mês registraram ocorrência na fase quente (fria) da ODP.

\section{CONSIDERAÇÕES FINAIS}

A pluviosidade anual em Abelardo Luz-SC, no período de 1958-2008, apresentou elevada variabilidade, fato já demonstrado em outros trabalhos (BUFFON et al., 2011; BUFFON \& BINDA, (no prelo)). Entretanto, ao se verificar os padrões dessa variabilidade, observa-se nitidamente a ocorrência de três períodos distintos, interpretados neste trabalho mediante correlação com as fases da ODP, a saber:

1. 1958-1978: representado pela ocorrência de fase fria da ODP, com maior ocorrência de episódios de La Niña, predominância de anos seco e tendentes a seco, com a redução dos totais pluviais mensais e eventos máximos por mês na escala de 0 a $20 \mathrm{~mm}$, tendo meses com ausência de precipitação;

1. 1979-1998: correlaciona-se com a fase quente da ODP, predomínio de eventos de El Niño, maior ocorrência de anos chuvoso e tendente a chuvoso, aumento nos totais pluviais mensais e períodos com ausência de eventos máximos por mês na escala de 0 a $20 \mathrm{~mm}$, tendo verificado nesse período um total pluvial diário de $210 \mathrm{~mm}$ e;

2. a partir de 1999: nova fase fria da ODP, com retrospectos semelhantes ao primeiro período.

Dessa forma, desvios positivos e negativos, embora dispersos ao longo de toda a série histórica abordada neste trabalho, foram intensificados pelas fases da ODP. Essas relações entre ODP e a ocorrência de EI Niño/La Niña (ENOS) são fundamentais para compreender a influência desses fenômenos sobre a sociedade. Buffon \& Binda (no prelo) reconhecem a importância dos mecanismos de teleconexões decadal na ocorrência de estiagens no município de Abelardo Luz (SC), bem como na ocorrência de inundações e alagamentos em Chapecó-SC, abordado por Binda et al. (2012).

Esses períodos, relacionados às teleconexões interanual e decadal, foram observados tanto na análise de escala mensal e anual, como, também, nos eventos máximos diários por mês. Com isso, identificou-se que o padrão verificado a partir de 1999 apresenta semelhança com a fase fria identificada entre 1958 a 1978 para o município de Abelardo Luz (SC). Desse modo, 
estima-se a ocorrência de uma condição pluviométrica próxima daquela que ocorreu ao longo da década de 60-70, ou seja, intensificação da ocorrência de estiagens no município.

Sanches et al. (2012), analisando dados de chuvas mensais em Alegrete (RS), no período de 1928 a 2009, identificaram que tendências negativas e positivas não são necessariamente decorrentes de mudanças climáticas, mas sim de um ciclo do próprio sistema. Nascimento Júnior (2011) verificou um padrão de variabilidade decadal na precipitação de São Miguel do Iguaçu (PR), Foz do Iguaçu (PR) e Quedas do Iguaçu (PR) que pode ser correlacionada com o padrão ODP de variabilidade decadal, embora não se prende rigidamente a fases. Prestes (2011) também aponta que a precipitação em Bagé (RS) apresentou influências da ODP, com destaque para a fase fria (ODP-). No Sul de Santa Catarina, Marques (2010), abordando a precipitação na Bacia do rio Tubarão (1946 a 2006) e as TSMS caracterizadas pela ODP, concluiu que a variabilidade da precipitação nessa região foi influenciada pelas distintas fases da ODP. Essas mudanças climáticas proporcionam alterações negativas e positivas nas interações sociedade na natureza, de modo, que as alterações negativas são mais importantes (MENDONÇA, 2006), uma vez, que podem gerar riscos a sociedade.

Baseados nas informações apresentadas neste estudo e em diversos trabalhos realizados na região Sul do Brasil, identificam-se evidências para acreditar que existem relações nítidas entre os padrões de teleconexão interanual e a variabilidade pluvial anual, como já apontado neste texto. Mas, ainda observam-se evidências de teleconexões de maiores escalas para a variabilidade pluvial, tal como: ODP. Uma vez que esse mecanismo altera tanto os padrões de menores escalas e, origina, assim, períodos distintos de variabilidade pluvial, embora as relações entre a ODP e a variabilidade pluvial não sejam diretas, esse fenômeno propicia períodos de inferiores e de elevados totais pluviais.

\section{REFERÊNCIAS}

ALEIXO, N. C. R; Pelas lentes da Climatologia e da Saúde Pública: doenças hídricas e respiratórias na cidade de Ribeirão Preto. Tese (Doutorado). Presidente Prudente: UNESP, 2012. $353 p$.

ANDRADE, A. R de. Variabilidade da precipitação pluviométrica na Bacia hidrográfica do Ivaí Paraná. Dissertação de mestrado. Maringá: UEM, 2003. 99p.

$A Y O A D E$, J. O. Introdução à climatologia para os trópicos. 13 ed. Rio de Janeiro: Bertrand Brasil, 2010.

BINDA, A. L.; BUFFON, E. A. M.; FRITZEN, M. Análise espaço-temporal dos casos de inundações e alagamentos registrados na cidade de Chapecó-SC (1980-2010). RA'E GA 26, 2012. p. 35-50.

BUFFON, E. A. M.; BINDA, A. L. Eventos de estiagens no município de Abelardo Luz-SC no período de 1960 a 1999. Revista Ciência e Natura, UFSM, (no prelo).

CAVALCANTI, I. F. A. \& AMBRIZZI, T. Teleconexões e suas influências no Brasil. In: CAVALCANTI, I.F.A. et al. (orgs) Tempo e Clima no Brasil. São Paulo: Oficina de Textos, 2009.

CONTI, J.B. Considerações sobre mudanças climáticas globais. SANT'ANNA NETO, J.L. \& ZAVATINI, J.A. Variabilidade e mudanças climáticas: implicações ambientais e socioeconômicas. Maringá: Eduem, 2000.

GALVANI, E. \& PEREIRA, A.R. El niño-oscilação sul (ENOS), quantificação e classificação da intensidade do fenômeno. X Congresso Brasileiro de Agrometeorologia, Piracicaba: ESALQ/USP, 1997. p.280282.

GRIMM, A. M. Variabilidade Interanual do Clima no Brasil. In: CAVALCANTI, I.F.A. et al. (orgs) Tempo e Clima no Brasil. São Paulo: Oficina de Textos, 2009a.

GRIMM, A. M. Clima da região Sul do Brasil. In: CAVALCANTI, I.F.A. et al. (orgs) Tempo e Clima no Brasil. São Paulo: Oficina de Textos, 2009b.

MARCELINO, E. V. \& GOERL, R. F. Inundação brusca. In: HERRMANN (Org.). Atlas de desastres naturais do Estado de Santa Catarina. Florianópolis, SC: IOESC, 2005. p. 93-96.

MARCELINO, E. V. Desastres Naturais e Geotecnologias: Conceitos Básicos. INPE-15208-PUD/193, Santa Maria, 2008, (Caderno Didático No 1), 38 p.

MARQUES, R. Precipitação na bacia hidrográfica na bacia hidrográfica do rio tubarão - sul de SC e Oscilação Decadal do Pacífico. In: Anais... $9^{\circ}$ Simpósio de Brasileiro de Climatologia Geográfica. Fortaleza. 2010.

MENDONÇA, F. A. \& DANNI-OLIVEIRA, I.M. Climatologia: noções básicas e climas do Brasil. São Paulo: Oficina de Textos, 2007.

MENDONÇA, F. A. Aquecimento Global e suas manifestações regionais e locais: alguns indicadores da região Sul do Brasil. Revista Brasileira de Climatologia, v. 2, 2006. p.71-86. 
MOLION, L. C. B. Aquecimento Global, El Niños, Manchas Solares, Vulcões e Oscilação Decadal do Pacífico. São José dos Campos - CPTEC/INPE. In: Climanálise, ano 3, n. 1, 2005. p. 1-5. Aquecimento global: uma visão crítica. In: Revista Brasileira de Climatologia, v.3/4, ago/2008a, p. 7-24.

. Perspectivas climáticas para os próximos 20 anos. Revista Brasileira de Climatologia, v. 3$\overline{4,2008}$ b, p. 117-128.

$$
\text { Aquecimento global: Natural ou Antropogênico. Disponível em: }
$$

http://www.cfh.ufsc.br/ laam/palestra/08.pdf. Acesso: 28 jul. 2010.

MONTEIRO, C. A. F. Análise Rítmica em Climatologia: problemas da atualidade climática em São Paulo e achegas para um programa de trabalho. (Série Climatologia n.1). São Paulo: USP/Instituto de Geografia, 1971, $21 \mathrm{p}$.

MOTA, F. S. Influência dos fenômenos el niño e la niña sobre o rendimento do arroz irrigado na região de Pelotas (RS). Revista Brasileira de Meteorologia, v.15, n.2, 2000, p.21-24.

NARDY, A. J. R. Geologia e petrologia do vulcanismo mesozóico da Região Central da Bacia do Paraná. Tese de Doutorado. Rio Claro: IGCE-UNESP, 1995.

NASCIMENTO JÚNIOR, L. As chuvas no Paraná: variabilidade interanual e decadal. 2011. 87 páginas. Trabalho de conclusão de curso em Geografia - Universidade Estadual de Londrina, Londrina, 2011.

NERY, J. T. Influência do fenômeno el niño na vazão da bacia do Rio Iguaçu-PR. XIV Congresso Brasileiro de Meteorologia, 2006, Florianópolis. Previsão e Sociedade. Florianópolis: EDUFSC, 2006. v. 01. p. 01-12.

NIMER, E. Climatologia do Brasil. 2.ed. Rio de Janeiro: IBGE, Depto de Recursos Naturais e Estudos Ambientais, 1989.

OLIVEIRA, F. N. M.; ARAUJO, R. L. C.; CARVALHO, J. S; SILVA, C. L. Inferência de mudanças climáticas na região de Manaus $(A M)$ usando dados geotermais e meteorológicos. Revista Brasileira de Geofísica. [online], vol.24, n.2, 2006, p. 169-187.

PELUSO JÚNIOR, V. A. O relevo do território Catarinense. Geosul, n.2, 1986. p.7-69.

PRESTES, S. D. Relações entre a Oscilação Decadal do Pacífico e a variabilidade da precipitação e Bagé RS. In: V Simpósio Internacional de Climatologia, João Pessoa (PB), 2011. Disponível em: http://sic2011.com/sic/arq/84215930674478421593067.pdf, acesso em 12 jun. 2013.

REBELLO, E. R. G. Oscilação decadal do pacífico e sua possível influência no regime de precipitação do rio grande do sul. Asociación Meteorológica Española. Disponível em: <http://www.ame-web.org/JORNADAS/1D_Rebello.pdf> acesso em 29 de março de 2014.

SANCHES, F. de O.; VERDUM, R.; FISCH, G. Análise das chuvas mensais em Alegrete (RS) no período de 1928-2009: um estudo de tendência. Revista Geonorte, Edição Especial 2, V.1, N.5, 2012. p.844-854.

SCHEIBE, L. F. A geologia de Santa Catarina. Geosul, n.1, 1986. p.7-38.

SILVA, M. V. da.; CAMPOS, C. R. J. de. Anomalias decadais do regime hídrico do RS no período de 1977 a 2006. Ciência e Natura, UFSM, 33 (1), 2011. p.75-89.

SLEIMAN, J.; SILVA, M. E. S. Padrões Atmosféricos associados a eventos extremos de precipitação sobre a Região Sul do Brasil. Revista do Departamento de Geografia, 20, 2010. p.93-109.

SPERLING, V; FERNANDES, V; MARQUES, J. R. Relação entre a Oscilação Decadal do Pacífico (ODP) e a precipitação de verão no Rio Grande do Sul. XVIII Congresso de Iniciação Científica, o XI Encontro de Pós-Graduação e a I Mostra Científica, 2009. Disponível em: <http://www.ufpel.edu.br/cic/2009/cd/pdf/CE/CE_01193.pdf>, acesso em 15 jan. 2013.

TAVARES, R.; SANT'ANNA NETO, J. L.; TOMMASELLI, J. T. G.; PRESSINOTTI, M. M. N.; SANTORO, J. Análise da variabilidade temporal e espacial das chuvas aos movimentos de massa no litoral norte paulista. In: SIMPÓSIO BRASILEIRO DE DESASTRES NATURAIS, 1.; 2004, Florianópolis. Anais... Florianópolis: GEDN/UFSC, 2004. p. 680-696. (CD-ROM). 